'A Accorsi, ${ }^{2} \mathrm{C}$ Lucci, ${ }^{1} \mathrm{G}$ Pizzolorusso, ${ }^{3} \mathrm{~L}$ Tubaldi, ${ }^{1} \mathrm{~F}$ Cerritelli, ${ }^{3} \mathrm{FP}$ Perri. ${ }^{1}$ European Institute for Evidence Based Osteopathic Medicine; ${ }^{2}$ Accademia Italiana Osteopatia Tradizionale Pescara; ${ }^{3}$ Neonatal Intensive Care Unit, Macerata Hospital, Macerata, Italy

Background and Aims The use of osteopathic manipulative treatment (OMT) in preterm infants has been documented and results from previous studies suggest the association between OMT and length of stay (LOS) reduction, as well as significant improvement in several clinical outcomes. The aim of the present study is to show the effect of OMT on LOS in a sample of premature infants. Methods A double blinded randomized controlled trial was conducted on preterm newborns admitted in a single NICU between 2010-2011. $\mathrm{N}=51$ subjects free of medical complications and with gestational age $>28$ and $<38$ weeks were enrolled and randomized in two groups: study group ( $\mathrm{N}=21)$ and control group $(\mathrm{N}=30)$. All subjects received routine pediatric care and OMT was performed to the study group for the entire period of hospitalization. Endpoints of the study included differences in LOS and daily weight gain.

Results Results showed a significant association between OMT and LOS reduction (mean difference between treated and control group: -1.787 ; $95 \%$ c.i. $-3.555,-0.0015$; $\mathrm{p}<0.05$ ). OMT was not associated to any change in daily weight gain.

Conclusions The present study confirms that OMT could play an important role in the management of preterm infants hospitalization.

\section{MANAGING ENT EMERGENCIES NEEDING TRANSFER TO PICU: THE EXTENDED TRANSPORT TEAM}

doi:10.1136/archdischild-2012-302724.0972

${ }^{1} \mathrm{M}$ Entwistle, ${ }^{2} \mathrm{~K}$ Parkins, ${ }^{3 R}$ Barber, 'S Santo. 'NWTS, CMFT; ${ }^{2}$ NWTS, Alder Hey Children's NHS Foundation Trust, Warrington; ${ }^{3 N W T S, ~ C M F T, ~ M a n c h e s t e r, ~ U K ~}$

Background Paediatric ENT emergencies are rare but can be lifethreatening and challenging to manage. In UK paediatric ENT services are centralised, and adult ENT surgeons and anaesthetist provide cover in local hospital (DGH). North West and North Wales Paediatric Transport Service (NWTS) UK is a specialist transport team.

Method Retrospective audit 12 months ENT transfers (NWTS database).

Results 74/932 (8\%) referrals had ENT diagnosis.

Feedback from DGH teams highlighted that advice from NWTS team including conference calls with Paediatric ENT helped optimise management.

Conclusion NWTS conference calls with Paediatric ENT specialists and local team improve patient management. Paediatric ENT consultants are occasionally required with NWTS team, providing expert advice and practical help. This data will help develop new regional intubation guidelines including recognition and management of the difficult paediatric airway.

\section{REGIONAL PAEDIATRIC INTENSIVE CARE (PIC) TRANSPORT SERVICES: BENEFITS OF 2 BECOMING 1 !}

doi:10.1136/archdischild-2012-302724.0973

B Lakin, K Parkins, C Walker, R Barber, S Santo, K Claydon-Smith. North West and North UK Paediatric Transport Service, Warrington, UK

Background Approximately 1.7 million children North West and North Wales (UK) and 600-700 are transferred annually from 31 hospitals into 2 regional PICUs.

Prior to 2010 specialist PIC transport teams were unit based but review (2007) revealed problems:

- Minimum 30\% PIC transfers by non-specialised teams (associated with adverse incidents)

- Poor access to clinical advice

- Delays finding PIC bed

- Delays mobilising specialist PIC transport team

- Adverse incidents associated with inexperienced medical personnel (specialist teams)

Regional Paediatric Transport Service (NWTS) started 2010 with a single point of contact providing advice, organisation transfer and PIC bed.

Methods Several database audits (first 12 months) to assess quality of retrievals compared to previous data.

Results $91.6 \%$ PIC transfers done by NWTS in first year (target > $85 \%)$.

Retrieval times (median) Mobilisation 29.5mins (pre NWTS 80mins); stabilisation 102 mins (pre NWTS 110mins); total retrieval time 201mins (pre NWTS 310mins)

Winter data consultant present $50 \%(n=40)$ retrievals - supporting inexperienced staff.

Snapshot (6 weeks) audit showed patient management advice was substantial and potentially avert admission. For example, 13 children were initially referred, but with advice over 3 (median) phone calls (range 2-8) remained in the local centre.

Better utilisation PIC beds refusal rate $5.8 \%$ versus $37 \%$ pre-NWTS.

Satisfaction survey (referring hospitals) demonstrated overall satisfaction excellent or good in domains including comparison with previous arrangements and clinical care.

Conclusions Our data suggest that improvement in quality has occurred since the launch of NWTS, including improved utilisation of regional PICU beds.

Abstract 972 Table 1 Results

\begin{tabular}{|c|c|c|c|c|c|c|}
\hline Causes & Infective & Neonate & Foreign Bodies & Elective & Injury & Post-Tonsillectomy \\
\hline Numbers & 36 & 13 & 10 & 8 & 4 & 3 \\
\hline Age & 5 months - 9yrs & $\begin{array}{l}5<24 \text { hrs old ( } 3 \\
\text { preterm) } 8 \text { older }\end{array}$ & 10 months -14 yrs & 6 days-5yrs & $1-5 \mathrm{yrs}$ & \\
\hline Diagnosis & $\begin{array}{l}\text { Croup, tracheitis, } \\
\text { parapharyngeal } \\
\text { abscess }\end{array}$ & Various & $\begin{array}{c}4 / 10 \text { respiratory } \\
\text { arrest }\end{array}$ & $\begin{array}{c}\text { Tracheal stenosis, } \\
\text { malacia, cystic } \\
\text { hygroma }\end{array}$ & $\begin{array}{l}\text { Trauma, caustic } \\
\text { ingestion }\end{array}$ & 2 with pre-op OSA \\
\hline Treatment & $\begin{array}{l}\text { Steroids, nebulised } \\
\text { adrenaline } \\
\text { +/- antibiotics }\end{array}$ & & $\begin{array}{l}\text { Removal in tertiary } \\
\text { centre }\end{array}$ & $\begin{array}{l}\text { Transferred for } \\
\text { complex intervention }\end{array}$ & $\begin{array}{c}\text { Steroids } \\
+/ \text { - antibiotics }\end{array}$ & \\
\hline Intubation & $\begin{array}{l}\text { 19/36 intubated 1/36 } \\
\text { LMA 16/36 resolved L } \\
\text { (not transferred) }\end{array}$ & $\begin{array}{l}\text { 11/13 } 1 \text { transferred } \\
\text { LMA (NWTS) } 1 \text { unable } \\
\text { to secure airway }\end{array}$ & $5 / 10$ & $\begin{array}{l}\text { All endotracheal tube } \\
\text { or tracheostomy }\end{array}$ & $4 / 4$ & $3 / 3$ \\
\hline $\begin{array}{l}\text { Paeds ENT advice } \\
\text { (Present) }\end{array}$ & $4 / 36(2)$ & 13/13 (3) & $10 / 10(0)$ & $8 / 8(0)$ & $4 / 4(0)$ & $3 / 3(0)$ \\
\hline
\end{tabular}




\section{PICU OUTREACH EDUCATION IMPROVES LOCAL MANAGEMENT OF STATUS EPILEPTICUS (SE)}

doi:10.1136/archdischild-2012-302724.0974

C Goedvolk, R Phatak. North West North UK Paediatric Transport Service, Warrington, UK

Background and Aims In september 2011 results of an audit on the acute management of SE in referring hospitals highlighting safety and feasibility of extubation in some children avoiding transfer to PICU were presented. We re-audited practice to determine whether education had an effect on local extubation rates.

Methods Audit of referral forms with a diagnosis of "seizures", "SE", "fit/fitting," "convulsion" and "epilepsy" from 1 September 2011 till 1 April 2012. Review of discharge summaries and notes of patients transferred to PICU.

Results 56 referrals for seizures (48 patients) in the 7 month period. At referral, 49 patients were intubated. 30 of 49 intubated patients were transferred to PICU, 19 extubated locally. 15 of 30 retrieved and 6 of 15 extubated patients had epilepsy.

Reasons for not attempting extubation included: ongoing seizures (2), Petechial rash (2), transfer for expert opinion (1), previous failed extubation (2) and refusal to assess (2).

All patients managed locally extubated within 6 hours. Extubation in PICU was after $<6(4),<12(7),<24$ (11) or $>24$ hours (3), data unavailable in 4.

1 patient was re-intubated locally because of further seizures. Conclusions We found an increase in safe extubations: 18.9\% prior and $38.7 \%$ after. This re-audit indicates that outreach education by PICU retrieval teams can achieve change in practice. It reconfirms that patients with SE transferred to PICU have a short duration of intubation. Refusal to assess feasibility of extubation by the local hospital can no longer be considered good medical practice.

\section{PERIPHERAL TISSUE NIRS OXIMETRY: REPRODUCIBILITY AND DYNAMIC RANGE OF INVOS 5100C, NONIN EQUANOX, AND FORE-SIGHT}

doi:10.1136/archdischild-2012-302724.0975

S Hyttel-Sørensen, T Witzner Hessel, G Greisen. Copenhagen University Hospital, Rigshospitalet, Copenhagen, Denmark

Background and Aims Near infrared spectroscopy (NIRS) could be a valuable tool in the NICU, but implementation into standard clinical care has yet to been seen. Different absolute values and dynamics of different devices and poor reproducibility could be the cause. Present study is a comparison between the adult sensors of INVOS 5100C, FORE-SIGHT and NONIN EQUANOX 7600.

Methods 10 repositionings on the same spot and 10 repostionings on slightly differing spots during steady state on the adult forearm followed by 6 cuff inflations to $250 \mathrm{mmHg}$ and subsequent tissue deoxygenation. Reproducibility was estimated by the within-subject standard deviation, $S_{w}$ and dynamic range by the difference between the pre- and post-cuff inflation $\mathrm{rStO}_{2} \Delta \mathrm{rStO}$

Results 10 adults participated. All with double skinfold less than $10 \mathrm{~mm}$.

Mean $\mathrm{rStO}_{2}$ was 71.1\% (CI 68.4-73.9\%), 68.1\% (CI 65.2$71.0 \%$ ), and $65.1 \%$ (95\% CI 63.3-67.0\%) with INVOS, NONIN, and FORE-SIGHT, respectively. INVOS gave significantly higher values than FORE-SIGHT $(p=0.003)$. All other differences were insignificant.

Reproducibility of FORE-SIGHT was best, while the reproducibility of NONIN was worst (table 1). Same-site reproducibility and various-site reproducibility was equal.

In pairwise comparisons $\Delta \mathrm{rStO}_{2}$ of NONIN, INVOS and FORESIGHT were significantly different (all $\mathrm{p}<0.0001)$ (table 2$)$.
The signal-to-noise ratio, i.e., $\Delta \mathrm{rStO}_{2} / \mathrm{S}_{\mathrm{w}}$ was $17.6,14.5$, and 12.5 for FORE-SIGHT, INVOS and NONIN, respectively.

Conclusion The different absolute values and dynamic ranges will make comparison of data collected with different devices difficult.

\begin{tabular}{|c|c|c|c|c|c|c|}
\hline & \multicolumn{2}{|c|}{ Same site } & \multicolumn{2}{|c|}{ Verious utes } & \multicolumn{2}{|c|}{ Overall } \\
\hline & S.(\%) & $\mathrm{Cl}(\mathrm{s})$ & S.(\$) & $c(s)$ & $S_{0}(8)$ & $\mathrm{Cl}(\boldsymbol{*})$ \\
\hline Evos & 2.9 & 2.4 .33 & 3.6 & 3.0 .4 .1 & 32 & 28.36 \\
\hline SONIN & 46 & 3.9 .53 & 38 & 93.4 & 4.2 & 3.8 .47 \\
\hline FORE-SRCHKT & 20 & $\{.7 .2\}$ & 2.4 & 20.2 .7 & 22 & 20.24 \\
\hline
\end{tabular}

Table 2. Dynamic range of the NIRS devices

\begin{tabular}{|c|c|c|}
\hline & $\Delta \mathrm{rStO}_{2}(\%)$ & $\mathrm{CI}(\%)$ \\
\hline INVOS & 46.6 & $44.9-48.2$ \\
\hline NONIN & 52.7 & $49.9-55.4$ \\
\hline
\end{tabular}

\section{CYCLOSPORINE-ASSOCIATED THROMBOTIC MICROANGIOPATHY AND THROMBOCYTOPENIA- ASSOCIATED MULTIPLE ORGAN FAILURE: A CASE SUCCESSFULLY TREATED WITH THERAPEUTIC PLASMA EXCHANGE}

doi:10.1136/archdischild-2012-302724.0976

${ }^{1} \mathrm{C}$ Ödek, ${ }^{1} \mathrm{~T}$ Kendirli, ${ }^{1} \mathrm{~A}$ Yaman, ${ }^{2} \mathrm{~T}$ I Ileri, ${ }^{3} \mathrm{Z}$ Kuloğlu, ${ }^{3} \mathrm{~A}$ Kansu, ${ }^{1} \mathrm{E}$ Ince. ${ }^{1}$ Pediatric Critical Care; 'Pediatric Hematology; ${ }^{3}$ Pediatric Gastroenterology, Ankara University, Faculty of Medicine, Ankara, Turkey

Introduction Thrombotic microangiopathy (TMA) is characterized by microvascular thrombosis, thrombocytopenia, and microangiopathic hemolytic anemia. Thrombotic thrombocytopenic purpura (TTP), hemolytic-uremic syndrome (HUS), and disseminated intravascular coagulation (DIC) are responsible from most of these cases. Secondary TMA syndromes are associated with sepsis/infection, cancer, transplantation, autoimmune diseases, and drugs. Studies showed that cyclosporine (CSA) is associated with TMA but the number of reported cases are very small.

Case Report A 13-year-old girl was adimitted to the pediatric intensive care unit (PICU) with multiple organ failure. She was diagnosed with polyglandular deficiency syndrome at an outside facility and had a history of celiac disease, autoimmune thyroiditis, and diabetes mellitus type I. CSA was started seven months before our PICU admission for persistent diarrhea. In PICU admission the patient was thrombocytopenic, anemic and she had multiple organ failure (renal, cardiovascular, hepatic, respiratory, and hematologic). Laboratory and clinical findings were consistent with TMA and TAMOF. TTP, HUS, DIC, and sepsis ruled out. We thought that CSA was the cause of TMA and TAMOF. CSA was stopped and five days of therapeutic plasma exchange (TPE) procedure performed. With TPE the patient improved clinically. Laboratory findings were normalized and after five days of TPE, TMA and MOF dissolved.

Conclusion CSA can be associated with TMA and TAMOF. The most commonly used strategy in treatment is the discontinuation of CSA. The experience in this case indicates that TPE may be effective in treatment of CSA-associated TMA and TAMOF especially in the presence of systemic TMA and MOF.

\section{THE CLINICAL CHARACTERISTICS AND MICROSURGERY FOR TUMORS IN THE FOURTH VENTRICLE TUMORS IN CHILDREN}

